\title{
EVALUATION OF THE “SPASTICITY OF CONJUGATE GAZE PHENOMENON" IN UNILATERAL CEREBRAL LESIONS
}

\author{
Eliana Teixeira Maranhão', Péricles Maranhão-Filho², Marco Antonio Lima²
}

\begin{abstract}
The spasticity of conjugate gaze phenomenon (SCG) is a subtle motor ocular sign that usually indicates unilateral acute cerebral lesion. We analyzed the sensitivity of this sign in a prospective blinded study using 57 patients. All patients had monohemispheric brain lesions without resting deviation of the eyes and no motor complaints. Fourteen individuals without cerebral lesions were included as controls. Patients and controls were submitted to a brain magnetic resonance image. We observed SCG in just 1/57 (sensitivity of $1.7 \%$ ), while all controls had a normal Bell's phenomenon. We speculate that SCG may disappear over time and is not useful to diagnose a long-lasting unilateral brain lesion.
\end{abstract}

KEY WORDS: spastic conjugate gaze phenomenon, brain tumor, semiology.

\begin{abstract}
Avaliação do "fenômeno do desvio conjugado espástico ocular" em lesões cerebrais unilaterais
RESUMO - O fenômeno do "desvio conjugado espástico ocular" é um sinal motor ocular sutil que habitualmente indica lesões cerebrais mono-hemisféricas agudas. Avaliamos a sensibilidade deste sinal num estudo prospectivo cego em 57 pacientes. Todos os pacientes apresentavam lesões cerebrais mono-hemisféricas, ausência de queixas motoras ou de desvio conjugado dos olhos em repouso. Quatorze indivíduos sem lesão cerebral foram incluídos como controle. Pacientes e indivíduos controle foram submetidos a exame de ressonância magnética do crânio. Observamos o sinal do desvio conjugado espástico ocular em somente $1 / 57$ pacientes (sensibilidade 1,7\%), enquanto todos os controles apresentaram o fenômeno de Bell. Especulamos que este sinal desaparece com o tempo, e que o mesmo não é útil para o diagnóstico de pacientes com lesões cerebrais monohemisféricas de longa duração.
\end{abstract}

PALAVRAS-CHAVE: fenômeno do desvio ocular conjugado espástico, tumor cerebral, semiologia.

The spasticity of conjugate gaze (SCG) is a subtle motor ocular sign of a monohemispheric cerebral lesion first noticed almost simultaneously by Prezzolini and Bárány in $1913^{1}$. It is described as a lateral conjugate deviation of the eyes to the side opposite of the lesion on attempted forced closure of the lids. This sign was present in patients with unilateral cerebral lesions in a series published by Cogan ${ }^{1}$. Later on, it was associated mainly, but not exclusively, to the presence of parietotemporal lesions ${ }^{2}$, and it was most recently observed in $70 \%$ of patients with radiologically proven unilateral acute cerebral lesions ${ }^{3}$.

In all previously studied groups, the patients had other clear signs of central nervous system lesions such as hemiparesia, hemianopia or aphasia.

The present study sought to determine the sensitivity of SCG as a sign of a long-lasting (over one month) monohemispheric lesion in patients with known brain tumors and no evidence of conjugate gaze paresis or other motor symptoms.

\section{METHOD}

Seventy one outpatients seen at the Department of Neurosurgery in the National Cancer Institute of Rio de Janeiro were enrolled in the study. Among these, 57 been diagnosed with monohemispheric brain tumor. All patients' symptoms had lasted longer than one month. Fourteen individuals without cerebral lesions were included as controls.

Patients and controls underwent complete neurological examination and were submitted to a brain magnetic resonance image (MRI) reviewed by the neurologists. Then they were blindly evaluated (no access to neurological data, clinical data, or image results) by one of us (ETM) with the "mini mental state examination" and specifically screened for some motor signs, including SCG.

\footnotetext{
${ }^{1}$ PT, Department of Physical Therapy, National Cancer Institute, Rio de Janeiro RJ, Brazil, Master Program Student, UFRJ. ${ }^{2}$ MD, PhD,
} Neurologist from Department of Neurosurgery, National Cancer Institute, Rio de Janeiro RJ, Brazil.

Received 9 October 2006, received in final form 16 January 2006. Accepted 9 March 2007.

Dra. Eliana Teixeira Maranhão - Avenida Canal de Marapendi 1680 / 1802 - 22631-050 Rio de Janeiro RJ - Brasil. E-mail: limaranhao@ gmail.com 
The SCG test consisted of standing in front of the patient and asking him to forcibly close both eyes so the examiner could elevate gently one lid at a time in order to observe the position of each eye (in his original article, Cogan ${ }^{1}$ shows a picture forcibly separating the lids simultaneously. Later, the same author published another study emphasizing that the lids had to be elevated one at a time ${ }^{2}$ ). In patients without brain lesions, the eyes usually deviate up or up and out (a normal Bell's phenomenon). The SCG is present when the eyes consistently deviate to one side, either right or left. Characteristically, the SCG is positive when the eye deviation occurs laterally to the side opposite to the cerebral lesion ${ }^{1}$. Patients were excluded if they had an obvious motor deficit, nystagmus, aphasia, apparent cranial nerve disease, movement disorders, non-neurological disorders that hindered neurological assessment, marked midline shift associated with a focal brain lesion, consciousness or cognitive impairment (MMSE $<25$ points) that could have affected their cooperation with the neurological examination, or brainstem, cerebellar, or bilateral cerebral lesions.

The study was approved by the National Cancer Institute Ethics Committee, and all patients signed the Informed Consent.

\section{RESULTS}

Among the 57 patients with unilateral brain disease (30 women $(51.8 \%)$ ), the mean age $( \pm S D)$ was $45.6( \pm 13.7)$ years. The histological diagnoses, as well as the localization of the lesions, are described in the Table.

The mean age of the controls was $54.7( \pm 14.2)$ years and $10(71.4 \%)$ were women.

The SCG was positive in only 1 of 57 patients $(1.7 \%)$. This patient was a 63 year-old woman who had a right frontal meningioma (Figure). Her eyes deviated consistently toward the left. All controls subjects showed a normal Bell's phenomenon during the test.

\section{DISCUSSION}

Lateral conjugate deviation of the eyes on attempted forced closure of the lids was emphasized by David G. Cogan in $1948^{1}$ when he observed the "spasticity of conjugate gaze" in the side opposite to the lesion in only 3 of $156(1.9 \%)$ persons with no known neurological disease, but in 34 of 54 (62.9\%) patients with unilateral cerebral diseases, and with no resting deviation of the eyes.

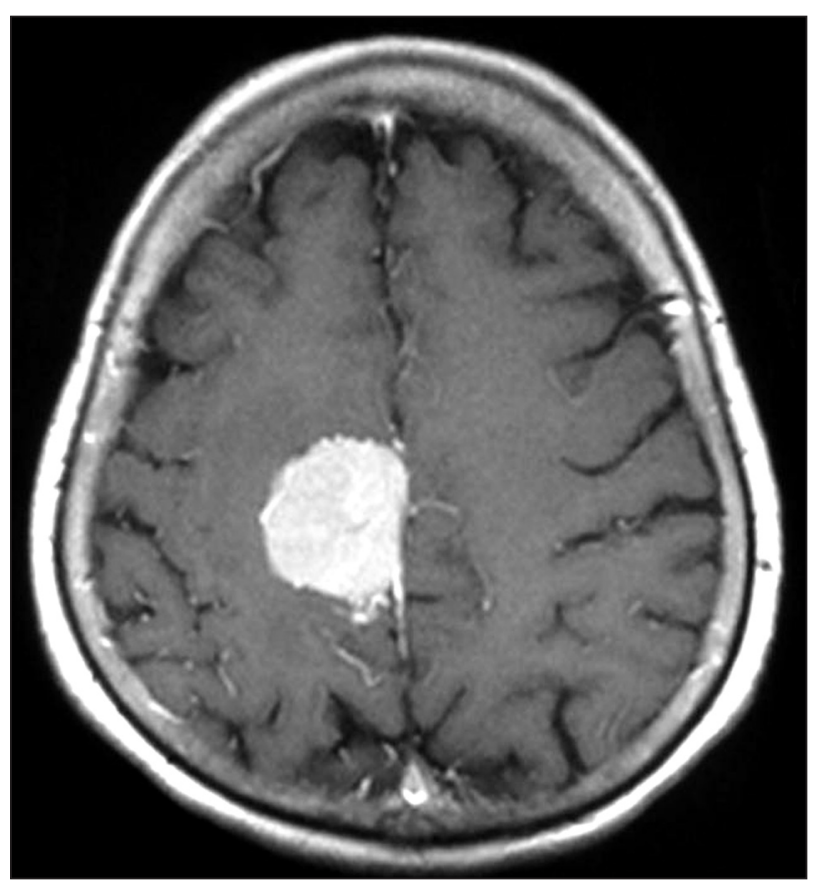

Figure. T1W axial magnetic resonance imaging following gadolinium infusion showing a right frontal meningioma.

Table. Histological diagnoses and localization of the brain lesions.

\begin{tabular}{lcccc}
\hline Hystological diagnosis & \multicolumn{4}{c}{ Lobes } \\
\cline { 2 - 5 } & Frontal & Temporal & Parietal & Occiptal \\
\hline Pilocytic astrocytoma & 7 & 1 & 0 & 0 \\
Anaplastic astrocytoma & 4 & 6 & 1 & 0 \\
Glioblastoma multiforme & 1 & 1 & 3 & 0 \\
Oligoastrocytoma & 1 & 1 & 2 & 0 \\
Meningioma & 6 & 4 & 5 & 0 \\
Metastasis & 0 & 0 & 3 & 0 \\
Ependymoma & 0 & 2 & 0 & 0 \\
Hemangioma & 0 & 1 & 0 & 0 \\
Neurocytoma & 0 & 0 & 1 & 0 \\
Ganglioglioma & 0 & 1 & 0 & 0 \\
Undetermined & 1 & 3 & 2 & 0 \\
\hline
\end{tabular}

The soma of numeric values represents the 57 tumors in respective lobes. 
In 145 patients of a neuro-ophtalmological service, Smith et al. ${ }^{2}$ found a normal Bell's phenomenon in 110 cases, and SCG in 35 (24.1\%) patients. Twenty four of these patients had evidence thought sufficient for topical localization of hemispheric brain lesion.

More than 30 years later, Sullivan et al. ${ }^{3}$ studied 35 patients, most with acute unilateral cerebral hemisphere lesions ( 9 frontal, 12 temporal, 16 parietal and 10 occipital), and registered SCG in 25 (71\%) of them. Sawyer et al. ${ }^{4}$ tested localizing signs in 62 patients with unilateral brain lesion. Most of them (79\%) displayed cerebral infarction. They found SCG in $40.6 \%$, but did not report on how long the patients had already been affected by the diseases.

In our patients, the SCG was negative in all but one (sensitivity 1.7), who had a right frontal lesion and SCG positive to the left. All controls subjects showed normal Bell's phenomenon.

It is generally accepted that each cerebral hemisphere represents a conjugate deviation system in equilibrium with the opposite side constantly influenced by visual fixation mechanisms, vestibular, proprioceptive, and somatosensory systems ${ }^{5}$. If this equilibrium is disturbed by hemispheric lesion, the position of the eyes will remain centered insofar as the visual macular fixation mechanism is properly functioning. However, conjugate deviation of the eyes will result if this visual reflex is interrupted by, for example, bilateral closure of the eyelids ${ }^{5}$.
The SCG phenomenon may be similar to the spastic hemiplegia after cerebral hemispheric lesions, when there is increased tonus on the side which, under appropriate conditions, is manifested as palsy, and when the fixation reflex is abolished, the eye deviates in the direction of great tonus ${ }^{1}$. Actually, though, the mechanisms through which this phenomenon occurs are not yet well understood ${ }^{6}$.

In conclusion, the SCG test may be rapidly and easily performed to detect acute unilateral intracranial lesions ${ }^{2-4}$, and it may be a good tool for the emergency room, where one needs to make a fast examinations. However, we can speculate that SCG may disappear over time, since all our patients had duration of symptoms longer than one month. Therefore, independent of the brain localization or the histology of the lesion, the SCG phenomenon is not valuable when attempting to localize long-lasting unilateral cerebral lesions.

\section{REFERENCES}

1. Cogan DG. Neurological significance of lateral conjugate deviation of the eyes on forced clousure of the lids. Arch Ophtalmol 1948;39:37-42.

2. Smith JL, Gay AJ, Cogan DG. The spasticity gaze phenomenon. Arch Ophtalmol 1959;62:694-696.

3. Sullivan HC, Kaminski HJ, Maas EF, Weissman JD, Leigh JL. Lateral deviation of the eyes on forced lid clousure in patients with cerebral lesions. Arch Neurol 1991;48:310-311.

4. Sawyer RN, Hanna JP, Ruff RL, Leigh RJ. Asymmetry of forearm rolling as a sign of unilateral cerebral dysfunction. Neurology 1993;43:15961598.

5. Lozano-Elizondo D. Two tests to elicit signs of spasticity of conjugate gaze. Am J Ophthalmol 1970;69:589-594.

6. Leigh JR, Zee DS. The neurology of eye movements. 3.Ed. New York: Oxford University Press; 1999. 